\title{
Comparative study of various optimization criteria for SDHWS and a suggestion for a new global evaluation
}

\author{
G. Fraisse $^{\text {a, } 1}$, Y. Bai ${ }^{\text {a }}$, N. Le Pierrès ${ }^{\text {a }}$ and T. Letz ${ }^{\text {b }}$ \\ ${ }^{a}$ Laboratoire Optimisation de la Conception et Ingénierie de l'Environnement, \\ Polytech'Savoie, Campus Scientifique Savoie Technolac, \\ 73376 Le Bourget du Lac Cedex, France \\ ${ }^{b}$ INES, Parc Technologique de Savoie Technolac, 50 avenue du Léman BP 258 \\ 73375 Le Bourget du Lac Cedex, France
}

\begin{abstract}
:
This study compares various optimization criteria for a solar domestic hot water system (SDHWS). First of all, we present the various parameters used to evaluate a SDHWS. We consider the energetic, exergetic, environmental $\left(\mathrm{CO}_{2}\right.$ emissions) and financial (life cycle cost) analysis. Various optimization criteria of a standard solar hot water system are then proposed. The optimized solutions are compared with a standard hot water system. The most suitable criteria take into account both energetic (therefore environmental) and financial evaluations. The most powerful solutions tend to increase the collector area - increasing the solar fraction during the mid-season - and reduce the tank volume, thereby decreasing the thermal losses and financial cost.

Some of the usual evaluation criteria for SDHWs cannot be used as optimization criteria because they do not consider the auxiliary heater, resulting in inaccurate indications of the system's performance. Therefore, it seemed important to propose a new evaluation method which integrates the life cycle savings, primary energy savings and $\mathrm{CO}_{2}$ emission savings with regard to a referenced solution based on a radar diagram of these three fractions. This mode of representation is particularly useful when various auxiliary heaters are compared.
\end{abstract}

Keywords: Optimization, SDHWS, simulation, global evaluation, mixed criteria

\footnotetext{
${ }^{1}$ Corresponding author: Tel. +33 4.79.75.88.95; Fax: +33 4.79.75.81.44

E-mail address: gilles.fraisse@univ-savoie.fr
} 


\section{INTRODUCTION}

In addition to being a clean energy, solar energy has the advantage of being an energy source that is available throughout the globe, with no losses attributable to transport. On the other hand, its highly variable input requires storage systems auxiliary heaters and specific control systems. Optimally combining solar and conventional systems for the most advantageous control, sizing, etc. is essential to obtaining high efficiency. Although there is an international standard defining the solar energy vocabulary (ISO, 1999), the performance parameters used to evaluate SDHWSs are numerous and it is never indicated clearly which value is the most relevant to evaluate or optimize a solar heating system: collector productivity, the solar fraction, efficiency, the fraction savings considering energetic, exergetic, environmental or economic criteria? The energy and economic criteria are most often used to optimize solar heating systems.

The economic criterion is often taken as the life cycle cost (LCC): it gives the financial cost of a domestic hot water systems over the life cycle (approximately 20 years) All the annual costs and savings are converted into present worth at a given interest rate and discount rate (Duffie and Beckman, 1991). Various types of SDHWs were thus optimized: thermosiphon systems (Lima et al., 2006) (Salazar et al., Web), forced-circulation systems (Kalogirou, 2004), direct-coupled photovoltaic and pump systems (Cardinale et al., 2003), and even a solar heating system combined with a wind power plant (Bakos and Tsagas, 2003).

The solar fraction (ISO, 1999) is widely used for both solar domestic hot water systems and combisystems. Numerous recent studies used this parameter as a reference: (Trillat et al., 2006; Badescu et al., 2006; Chow et al., 2006; Jordan and Furbo, 2005; Lund, 2005).

From an exergetic point of view, numerous studies have been conducted to optimize components (collector, storage tank) or the overall system (Singh et al., 2000; Torres-Reyes and Gortari, 2001; Torres-Reyes et al., 2003; Xiaowu and Ben, 2005; Gunerhan and Hepbasli, 2007; Fernandez-Seara et al., 2007; Zmeureanu and Wu, 2007; Hepbasli, 2007). Such systems generally have low exergetical efficiency because of the energy quality degradation of the incident solar irradiation incident on the collector (stemming from a solar source with a temperature greater than $5800 \mathrm{~K}$ ) towards a quantity of heat close to the ambient temperature. Another definition can be used by taking into account the Carnot coefficient at the collector's temperature instead of the sun's temperature (Le Pierrès, 2005).

The objective of energy optimization is generally to minimize a function including energy consumption, solar production and a penalty when the water tap temperature is lower than the set-point (Prud'homme and Gillet, 2001): 


$$
J=\int_{\text {time }}\left[\left(P_{\text {elec }}+P_{\text {pump }}-P_{\text {sol }}\right)+\alpha \cdot\left(T_{s 1}-T_{\text {set }}\right)^{2}\right\rfloor d t
$$

with $P_{\text {elec }}$ the electrical consumption of the auxiliary heaters [W]; $P_{\text {sol }}$ the solar energy collected [W], $P_{\text {pump }}$ the power required by the pump to drive the fluid in the collector loop [W]; $T_{s l}$ the temperature in the upper part of the storage tank $\left[{ }^{\circ} \mathrm{C}\right], T_{\text {set }}$ the set-point temperature $\left[{ }^{\circ} \mathrm{C}\right], \alpha$ is a trade-off factor.

Mixed criteria are also used as criteria for optimization. For example, the ratio of the additional investment cost by the primary energy savings (€/kWh-ep) can be estimated and compared to a reference system. In the (Bales, 2002) study, the author compared the performance of a generic combisystem (space heating store with DHW load side heat exchanger and an external auxiliary), using several optimization criteria: the combisystem criterion and the fraction saving indicator, which includes the penalty function of the solar combisystem in the fractional energy savings. Up to ten parameters were optimized: e.g., the auxiliary heated tank volume, the thermostat setting for the auxiliary heated area, the position and size of the DHW heat exchangers, the insulation thickness and the collector area. Another study was based on the annuity of the overall investment (20 years of operation) over the annual solar heat delivered to the tank (Krause et al., 2002). Compared with the initial system (the estimated solar heat cost of this system is $9.7 \mathrm{c} € / \mathrm{kWh}$ ), the best configuration reduced the ratio (18\%), because it increased solar energy use and reduced the initial investment. One of the most widely used numerical tools to simulate solar heating systems is the TRNSYS software (Klein et al., 1996). As regards optimization, various software packages have been developed such as Optilib (Gabriele and Ragsdell, 1984) and Genopt (Wetter, 2004). Most optimization algorithms are adapted to the SDHWs: genetic algorithms, Hooke-Jeeves algorithms, etc. (Krause et al., 2002; Wetter and Wright, 2003). This study provides the various quantities necessary to evaluate a system considering energetic, exergetic, environmental and economic criteria. We considered a conventional installation (without a solar heating system) and a standard solar installation, and compared the optimized solar installations based on energetic, environmental, economic and mixed criteria. The optimization was carried out by combining TRNSYS and GenOpt simulation program. The TrnOpt component of the TESS library (www.tess-inc.com) was the interface between both software packages. The optimized parameters were the collector area, the tank volume and the flow rate in the collector loop. Finally, a global approach to evaluation based on the radar diagram of three kinds of savings (primary energy, $\mathrm{CO}_{2}$ emissions and financial cost) will be proposed.

\section{The evaluation criteria}


The energetic and thermal quantities for a conventional domestic hot water system (without a solar heating system) and a standard SDHW with an integrated auxiliary heater (electric or heat exchanger) will be described first. On the basis of these values, the evaluation criteria of SDHWs will be presented.

\subsection{Description of a conventional installation}

Fig. 1. shows the diagram of a conventional installation with an integrated auxiliary heater. The net energy demand for the tank set-point temperature $T_{\text {set }}$ is Qnet $_{\text {conv }}$. The tank thermal losses are $Q l_{\text {conv }}$. The energy supplied to the cold water between the inlet and outlet of the tank is $Q d_{\text {conv }}$. The tank energy balance is:

$$
\operatorname{Qnet}_{\text {conv }}=Q l_{\text {conv }}+Q d_{\text {conv }} \quad(\mathrm{kWh})
$$

The final energy $Q f_{\text {conv }}$, which is the energy as the consumer receives it, is obtained from Qnet $_{\text {conv }}$ with the transformation efficiency $\eta f-n e t_{c o n v}$. Also, the primary energy $Q p_{\text {conv }}$ is obtained from $Q f_{\text {conv }}$ with $\eta p-f_{\text {conv }}$.

$$
\begin{aligned}
& Q f_{\text {conv }}=Q n e t_{\text {conv }} / \eta f-n e t_{\text {con }} \quad(\mathrm{kWh}) \\
& Q p_{\text {conv }}=Q f_{\text {conv }} / \eta p-f_{\text {conv }} \quad(\mathrm{kWh})
\end{aligned}
$$

The coefficient of performance of the conventional installation is:

$$
C O P_{\text {conv }}=Q d_{\text {conv }} / Q f_{\text {conv }}
$$

To take into account periods when the water tap temperature $T h w$ is lower than the set-point temperature $T_{s e t_{l}}$ (typically $55^{\circ} \mathrm{C}$ ), penalty energy $Q_{l}$ needed to heat the water from $T h w$ to $T_{s e t}$ is considered. The temperature Thw can be less than set $_{l}$ because of the off-peak hour and peak hour rates. The peak hour period forbids electrical water heating. We note Qnet $_{\text {pen-conv }}$ the expression of Qnet $_{\text {conv }}$ integrating the penalties $Q_{1}$ and $Q_{2}$.

$$
Q_{1}=\max \left(0, \Delta t \cdot \dot{m}_{3} \cdot C p \cdot\left(\operatorname{Tset}_{1}-T h w\right)\right)
$$

With $\quad m_{3}$ the water tap mass flow rate $[\mathrm{kg} / \mathrm{s}] ; \Delta t$ the time step [s]; $C p$ specific heat $[\mathrm{J} / \mathrm{kgK}]$

In addition, we added an equation that can penalize the installation when the water tap temperature $T h w$ is lower than the set-point Tset $_{2}\left(\right.$ Tset $_{2} \leq$ set $\left._{1}\right)$ :

$$
Q_{2}=\max \left(0, \Delta t \cdot \dot{m}_{3} \cdot C p \cdot\left(\text { Tset }_{2}-T h w\right)^{X}\right)
$$

The temperature $\mathrm{Tset}_{2}$ corresponds to the temperature limit below which the discomfort is penalized. The penalty level is expressed with the parameter $X$, representing the degree of discomfort. A value $X=4$ means almost forbidding the periods when $T h w \leq T s e t_{2}$, whereas a value $X=2$ is much less penalizing. In that case, we accept some periods of discomfort as long as they are rare and it reduces the installation size. 
Similarly, as in the study on solar combisystems (Weiss, 2003), we defined the heat demand penalty $Q d_{\text {pen-conv }}$, which integrates both quantities $Q_{1}$ and $Q_{2}$. It compares several installations with the same loads and does not reach unacceptable solutions:

$$
Q d_{\text {pen-conv }}=\Delta t \cdot \dot{m}_{3} \cdot C p \cdot\left\{\max \left(0,\left(\text { Sset }_{1}-T h w\right)\right)+\left[\max \left(0,\left(\text { set }_{2}-T h w\right)\right)\right]^{X}\right\}
$$

The final energy $Q f_{\text {pen-conv }}$ was obtained from $Q n e t_{\text {pen-conv }}$ (which is the sum of $Q n e t_{\text {conv }}$ and $Q d_{\text {pen-conv }}$ ) by integrating the efficiency $\eta f-n e t_{c o n v}$. Also, the primary energy $Q p_{\text {pen-conv }}$ was obtained from $Q f_{\text {pen-conv }}$ with $\eta p$ $f_{\text {conv }}$.

$$
\begin{array}{ll}
Q f_{\text {pen-conv }} & =Q n e t_{\text {pen-conv }} / \eta f-n e t_{\text {conv }} \quad(\mathrm{kWh}) \\
Q p_{\text {pen-conv }} & =Q f_{\text {pen-conv }} / \eta p-f_{\text {conv }} \quad(\mathrm{kWh})
\end{array}
$$

2.2. Description of the solar installation with an integrated auxiliary heater (Duffie and Beckman, 1991 ; Peuser et al., 2005)

The diagram of the solar installation is shown in Fig. 2. Since the outlet tank temperature can be greater than $T_{s e t}$, mixing with cold water $(T c w)$ is necessary, not to exceed $T_{s e t}$. The energy demand for the set-point Tset $_{1}$ is Qnet $_{\text {aux }}$. As previously, the heat demand penalty $Q d_{\text {pen }}$ (same definition as equation (8)) is added to Qnet $_{\text {aux }}$. The tank's heat losses are $Q l$. The energy supplied to the cold water between the inlet and outlet of the tank is $Q L$.

The final energy $Q f_{\text {aux }}$ (respectively $Q f_{\text {pen-aux }}$ ) is obtained from $Q n e t_{\text {aux }}$ (respectively $Q$ net $t_{\text {pen-aux }}$ which is the sum of $Q n e t_{\text {aux }}$ and $\left.Q d_{p e n}\right)$ by using the efficiency $\eta f-n e t_{a u x}$. The additional electric consumption of the solar system (pump and controller) should be integrated into $Q f_{a u x}$. Also, the primary energy $Q p_{a u x}$ (respectively $\left.Q p_{\text {pen-aux }}\right)$ is obtained from $Q f_{\text {aux }}$ (respectively $\left.Q f_{\text {pen-aux }}\right)$ with $\eta p-f_{\text {aux }}$.

The incident solar energy on the collector (area: $A c)$ is $H\left(\mathrm{kWh} / \mathrm{m}^{2} . \mathrm{year}\right)$. The energy transmitted by the solar collector to the heat transfer fluid is Qcol. The heat losses from the collector loop are Ql,pipe. The solar energy supplied by the collector loop to the tank is $Q$ sol. The thermal balances are:

$$
\begin{aligned}
& \text { Qnet }_{\text {aux }}+Q \text { sol }=Q l+Q L \quad(\mathrm{kWh}) \\
& Q d=Q L \quad(\mathrm{kWh}) \\
& Q c o l=Q l, p i p e+Q \text { sol } \quad(\mathrm{kWh})
\end{aligned}
$$

We also defined the solar installation's coefficient of performance $(C O P)$ : 


$$
C O P=Q d / Q f_{\text {aux }}
$$

\subsection{The various evaluation criteria}

\subsubsection{Energetic quantities}

The main quantities used to evaluate the energetic performance of SDHWs are shown as:

- Solar collector productivity:

$$
\text { Prod }=\text { Qcol } / \text { Ac } \quad\left(\mathrm{kWh} / \mathrm{m}^{2}\right)
$$

- Collector efficiency:

$$
\eta \operatorname{col}=Q \operatorname{col} /(H . A c)
$$

- Solar fraction = "energy supplied by the solar plant of a system divided by the total system load" (ISO, 1999):

$F s o l=Q s o l / Q d$

In the case of an integrated auxiliary heater, it is very difficult to determine the exact amount of energy supplied by the solar hot water system to the conventional part of the system. For this reason, we considered the energy supplied by the heat exchanger.

- Sometimes a different definition of the solar fraction Fsol is used (e.g. in the Polysun software http://www.solarenergy.ch and T-Sol http://www.solardesign.co.uk):

$F$ sol' $=$ Qsol / $\left(\right.$ Qsol + Qnet $\left._{\text {aux }}\right)$

- $\quad$ Final energy savings:

$Q f-s a v=\left(Q f_{\text {conv }}+Q f_{\text {pen-conv }}\right)-\left(Q f_{\text {aux }}+Q f_{\text {pen-aux }}+Q p a r\right) \quad(\mathrm{kWh})$

with Qpar the parasitic energy for the collector loop (pump, the control unit, and possibly the boiler pump)

- $\quad$ Primary energy savings:

$Q p-s a v=\left(Q p_{\text {conv }}+Q p_{\text {pen-conv }}\right)-\left(Q p_{\text {aux }}+Q p_{\text {pen-aux }}+Q p a r * 2.58\right) \quad(\mathrm{kWh})$

(The term 2.58 is usually used in France to convert electrical energy into primary energy)

- The final energy fractional rate:

$F s a v-f=Q f-s a v /\left(Q f_{c o n v}+Q f_{\text {pen-conv }}\right)$

- The primary energy fractional rate:

$F s a v-p=Q p-s a v /\left(Q p_{c o n v}+Q p_{\text {pen-conv }}\right)$ 


\subsubsection{Exergetic quantities}

Exergetic efficiency not only takes into account the quantities of energy used, but also their quality. The exergetic efficiency $\eta e x$ of the solar system with an integrated auxiliary heater is obtained with the equation:

$$
\eta e x=\frac{\int \dot{m}_{3}(t)\left[h_{T h w}-h_{T c w}(t)-T a(t) \cdot\left(S_{T h w}-S_{c w}(t)\right)\right] d t}{\mathrm{Qf}_{\mathrm{aux}}+\mathrm{Qf}_{\mathrm{pen- \textrm {a } u x}}+\mathrm{Qpar}+\int G(t) \cdot A c \cdot\left(1-\frac{T a(t)}{\operatorname{Tabs}(t)}\right) d t}
$$

with $T a$ the ambient air temperature $[\mathrm{K}]$; Tabs the absorber temperature $[\mathrm{K}] ; h$ the water specific enthalpy

$[\mathrm{J} / \mathrm{kg}] ; S$ the water entropy $\left[\mathrm{J} /(\mathrm{kg} . \mathrm{K}] ; G\right.$ the solar radiation $\left[\mathrm{W} / \mathrm{m}^{2}\right]$

The numerator of this equation represents the exergy gain of the water supplied to users (Gunerhan and Hepbasli, 2007). The denominator is the exergy entering the system: the electrical energy is pure exergy but the heat transferred to the solar panel is weighted by the Carnot factor (Stitou et al, 2000; Sorin et al, 2002).

\subsubsection{Environmental quantities ( $\mathrm{CO}_{2}$ emissions)}

A solar installation can save energy that would have been supplied by a conventional heating system and that would have produced greenhouse gases. This quantity of greenhouse gases depends on the quantity of the conventional energy saved. By calculating the energy saved, we can calculate the reduction in greenhouse gases. In France, the quantity (kg) of $\mathrm{CO}_{2}$ per kWh-PCI avoided for the DHWS is (ADEME, 2005):

\begin{tabular}{ll}
\hline Natural gas & 0.234 \\
Fuel oil & 0.300 \\
Calor or butane gas (LPG) & 0.234 \\
Electricity & 0.040 \\
\hline
\end{tabular}

The electricity value is very low because of the huge proportion of nuclear energy used in France. We calculated the mass of non-emitted $\mathrm{CO}_{2}\left(m_{\mathrm{CO} 2}\right)$ and the fractional savings of $\mathrm{CO}_{2}$ with regard to the conventional solution $\mathrm{Fsav}_{-} \mathrm{CO}_{2}$.

2.3.4. Economic quantities (life cycle cost) (SAE, 1995; Fuller and Petersen, 2002)

The life cycle cost (LCC) method considers the costs and savings over the life cycle of the system, which is roughly 20 years for a SDHW. Optimizing the system means obtaining the lowest LCC or the highest life 
cycle savings (LCS). The annual costs and savings are converted into present worth values at a given interest rate and discount rate.

The calculation of the solar heating system cost includes (see Annex 1):

- Initial investment: calculated according to the cost of the equipment and manpower associated with the installation of the system, and the tax reduction allowed (50\% on the equipment in France, after having deducted the grants available)

- $\quad$ Annual maintenance and operation costs

The cost of a conventional installation consists in costs relating to the hot water tank, manpower, and annual operation and maintenance.

The annual savings (Sav) is the difference in maintenance and operation costs between the conventional and the solar installation. The additional investment cost between the solar and conventional installations are noted as $A I$.

By assuming equal yearly payments $Y P$, the life cycle cost is calculated using the follow equation:

$$
L C C=I+K * Y P \quad(€)
$$

with I the investment [year 0]; YP the annual payments

$$
\begin{aligned}
& K=\frac{r \cdot\left(r^{n}-1\right)}{r-1} \\
& r=\frac{1+i}{1+d}
\end{aligned}
$$

with $i$ the interest rate (0.02 in France); $d$ the discount rate (0.04 in France); $n$ is given as 20 years (life cycle of the system)

The inflation rate corresponds to the increase in the cost of living. The discount rate makes it possible to return financial streams that are not directly comparable, because they occur at different dates, on the same basis. It can not only compare them but can also make arithmetic operations on them. The life cycle savings (LCS) over the life cycle can be calculated.

$$
L C S=K * \operatorname{Sav}-A I \quad(€)
$$

with $A I$ the additional investment[€]; Sav the annual savings (€)

It is also possible to calculate the pay back time:

$$
N=\frac{\operatorname{Ln}\left(1+\frac{A I}{\operatorname{Sav}} \cdot \frac{r-1}{r}\right)}{\operatorname{Ln}(r)}
$$


Finally, we define the financial fractional savings compared with a conventional solution (without a solar heating system):

$F s a v-L C C=L C S /(L C C)_{\text {conventional }}$

\section{Optimization based on various criteria}

\subsection{Description of the cases studied}

\subsubsection{The installations studied}

The characteristics of the conventional and solar installations are described in Annex 2. Only the electric auxiliary heater was studied. The energy demand for hot water was $3450 \mathrm{kWh}$ per year $\left(2001\right.$ at $\left.55^{\circ} \mathrm{C}\right)$. The weather conditions corresponded to the city of Lyon. The cold water temperature varied between 9 and $19^{\circ} \mathrm{C}$ over the year. The price of electricity was $0.1074 € / \mathrm{kWh}$ with the auxiliary heater functioning during the periods $2 \mathrm{~h}-6 \mathrm{~h}, 12 \mathrm{~h}-14 \mathrm{~h}$ and $20 \mathrm{~h}-24 \mathrm{~h}$. This price was applied to $Q f_{\text {conv }}, Q f_{\text {pen-conv }}, Q f_{\text {aux }}, Q p a r$ and $Q f_{\text {pen-aux }}$. The manpower cost of the solar installation was set at $1688 €$ (taxes included) for reasons of simplification. On the other hand, the cost of the equipment depended on the size of the collector and the tank (see Annex 1).

The efficiency coefficients of the conventional and solar installations (electrical auxiliary heater) were:

$$
\begin{aligned}
& \eta f-n e t_{c o n v}=\eta f-n e t_{a u x}=0.95 \\
& \eta p-f_{c o n v}=\eta p-f_{a u x}=1 / 2.58
\end{aligned}
$$

The tank set-point temperature was $T$ set $_{1}=55^{\circ} \mathrm{C}$ and the comfort penalty was calculated from the temperature $\operatorname{Tset}_{2}=40^{\circ} \mathrm{C}(X=2)$.

The mass of non-emitted $\mathrm{CO}_{2}$ was calculated by using the $0.089 \mathrm{~kg}$ value per $\mathrm{kWh}$ of electricity saved (this value was much lower than the European average).

\subsubsection{The optimization criteria studied}

The optimized parameters were the collector area, the tank volume and the collector loop flow rate. We limited the number of parameters to be optimized so as to simplify the comparisons. Various optimization criteria were used. The performance quantities were the following:

- $\quad$ Energetic criterion (to be minimized): $Q f_{\text {aux }}+Q f_{\text {pen-aux }}+Q p a r$

(optimizing in terms of Fsav-f)

- Exergetic criterion (to be maximized): $\quad$ pex

- Financial criterion (to be minimized): $L C C$ 
- $\quad$ Mixed criterion 1 (to be maximized): Fsav-f* Fsav-LCC

- $\quad$ Mixed criterion 2 (to be minimized): $\left(Q_{\text {net }} t_{a u x}+Q d_{p e n}+Q l\right) / Q s o l$

- $\quad$ Mixed criterion 3 (to be minimized): $A I / Q f$-sav

(€/kWh)

Mixed criterion 1 was designed to reflect the highest financial savings combined with the final energy savings to obtain a compromise between these two criteria. The second mixed criterion was the ratio of the energies to be minimized (tank losses, auxiliary heating and comfort penalties) divided by the energy to be maximized (the solar energy supplied to the tank). Therefore, mixed criterion 2 will be noted Qmin / Qsol. The third criterion was used in the (Bales, 2002) study; it reduced the additional investment with regard to the energy saving.

The optimization was carried out using the Hooke-Jeeves method (Wetter and Wright, 2003). We used the default values of the interface TrnOpt, which combines TRNSYS (Klein et al., 1996) and GENOPT (Wetter, 2004) software. The optimization algorithm makes it possible to set the minimal and maximal values for each of the optimized parameters. The following values were considered:

- Collector area: 2-10 $\mathrm{m}^{2}$ (initial: $6 \mathrm{~m}^{2}$ )

- $\quad$ Tank volume: $0.2-0.6 \mathrm{~m}^{3}$ (initial: $0.4 \mathrm{~m}^{3}$ )

- $\quad$ Flow rate in the collector loop: 5-65 1/h.m² (initial: 35 1/h.m²)

We did not consider the initial values of these three parameters identical to the solar standard installation (see Annex 2) so as not to be too close to an a priori high-performance installation. The tank was modeled with the TRNSYS TYPE 140 considering 20 temperature nodes. The tank exit temperature was mixed with the cold water temperature using a three-way valve, noted Thw. Annual simulations were carried out with a 12-min time step.

\subsection{The optimization results}

The objective of the optimization was not to look for a common solution because the results depended directly on the hypotheses. These vary widely considering the SDHWS design (we assumed, for example, a relative height of the auxiliary heater in tank of 0.5), financial costs (interest and discount rates, energy price, the grants, etc. (see Annex 1)). On the other hand, comparing the solutions obtained can indicate which optimization criteria are the most relevant.

\subsubsection{Improvements obtained on each of the optimized criteria}


The improvement on the optimized solar installations compared to the standard solar installation with each of the criteria is shown in Table 1 . The improvement on each criteria ranges from $10 \%$ to $256 \%$.

Figure 3 shows the variation of each of the optimized parameters and the performance values during the iterations in the case of the $L C C$ optimization. It can be seen that $L C C$ performance decreased during the iterations. The variations in $L C C$ did not decrease continuously because of the optimization method retained. The Hook-Jeeves method tests new parameters based on the preceding parameters by considering an increase or a decrease, which explains the discontinuous progression of the $L C C$. The optimization stops automatically depending on the parameter defining the maximum number of step reductions. The performance values do not change much after 22 iterations. The minimum $L C C$ value was obtained at the 40th iteration; the parameter values were then $8.3 \mathrm{~m}^{2}, 3131$ and $17.2 \mathrm{l} /\left(\mathrm{h} \cdot \mathrm{m}^{2}\right)$. These sizing parameters do not necessarily correspond to the material made available by manufacturers. Ideally, one would vary each parameter during the optimization phase by taking into account the data for each of the components actually available.

\subsubsection{Presentation of all the results}

Table 2 shows most of the evaluation criteria for the standard solar installation, the conventional solution (last column) and all the solar solutions obtained after optimization. The values of the parameters are indicated at the top of the table.

Optimizing a single criterion is not necessarily judicious in that because there is a risk of obtaining lower performance for the non-optimized criteria. The energy savings $(F s a v-f)$ is always greater than the financial savings (Fsav-LCC) considering the low price of electricity and the additional investment for the solar plant. A substantial increase in the price of energy could balance both savings rates.

If only these two criteria are relevant, it is easy to classify the optimized solutions with Fig. 4. A solution will provide greater performance in terms of these two criteria the farther the point is from the origin of axes, i.e. the higher the product Fsav-LCC by Fsav-Ef is (mixed criterion 1). Mixed criteria 1 and 2 offer the best performance, followed very closely by the $L C C$ and energy criteria. The last two criteria are $A I / Q f-s a v$ and exergy. The exergy criterion favors energy performance, whereas the AI/Qf-sav mixed criterion seems to benefit financial performance. Therefore, the most helpful criteria are the four criteria: mixed criteria 1 and 2 , energy and $L C C$. The performance thus obtained for this group is approximately $F s a v-L C C=14 \%$ and $F s a v-$ $E f=67 \%$. The standard solar configuration seems much less attractive $(F s a v-L C C=6 \%$ and $F s a v-E f=47 \%)$. 
This demonstrates the potential of performance improvement based on combining an optimization tool with an energy system simulation tool.

It is important to note that energy and mixed criteria 2 do not directly take the cost of the installation into consideration. Consequently, one risks obtaining the collector's oversize area if a large variation is brought into play. Moreover, the collector's area obtained with these two criteria corresponds to the maximum value authorized in our study $\left(10 \mathrm{~m}^{2}\right)$. This value corresponds to double the standard sizing (approximately $5 \mathrm{~m}^{2}$ ) and can be considered to be oversized. A larger variation range was not used so as not to penalize the calculation time. The $L C C$ and mixed criteria 1 integrate both installation cost and energy consumption. It will be necessary to consider the $L C C$ if we wish to encourage reducing the installation pay-back time, and mixed criterion 1 to obtain an energy and financial compromise. Even if the progression in energy prices is an unknown over the life cycle of the installation, it seems necessary to take cost into account. Knowing that the price of energy can only increase, the pay-back time of the installation will actually be lower.

Other mixed optimization criteria were studied, but not presented in this study, for example mixed criterion 4 , which consists in minimizing the cost and the final energy with regard to a reference solution (solar installation or not) in the following way:

- $\quad$ Mixed criterion $4:\left(L C C / L C C_{\text {ref }}\right)^{2}+\left(\left(Q f_{\text {aux }}+Q f_{\text {pen-aux }}+Q p a r\right) / Q f_{\text {ref }}\right)^{2}$

- Solar Fraction: Fsol'

These criteria are very successful because they provide results that are very close to mixed criterion 1 . The optimization criterion Fsol' presents the problem of not integrating the financial cost. The solution obtained therefore risks being oversized (moreover, the maximum collector area was obtained in this case). Nevertheless one should not lose sight of the technological feasibility of the optimized solution. For example, over-sizing the solar collector requires a specific device that can prevent the risks of deterioration caused by over-heating (with an additional cost that should be taken into account).

The disadvantage of Fig. 4 is that it does not integrate the environmental issue (primary energy and greenhouse gas emissions). The following will illustrate how to define a global evaluation.

\section{- Energy issue}

The high solar fraction Fsol is obtained in the summer period (roughly 150\%), providing the best solutions because the areas are high $\left(9.9 \mathrm{~m}^{2}\right.$ for mixed solution 1$)$, providing an incentive to over-size the collector area so as to increase solar gains during the mid-season. Nevertheless, monitoring the system for over-heating during the summer period will remain necessary (technological systems are used with combisystems). 
For all the solar installations, the parasite energy used by the pump and controller is not low since it accounts for approximately $5.7 \%$ of the final energy from the auxiliary heater $Q f_{\text {aux }}$ when $L C C$ is optimized (flow rate, $17.2 \mathrm{l} / \mathrm{h} \cdot \mathrm{m}^{2}$ ) and $7.7 \%$ for the exergetic optimization (flow rate, $65 \mathrm{l} / \mathrm{h} \cdot \mathrm{m}^{2}$ ). It is therefore normal that the energy optimization tends to reduce the fluid flow rate compared to a standard solar installation. A direct coupling of a photovoltaic module with the pump would save parasite energy.

The coefficient of performance $(C O P)$ of the best solution is approximately $2.5,1.4$ in the standard solar installation and only 0.7 in the conventional solution.

High collector efficiency is not necessarily synonymous with optimal performance. The efficiency in the standard configuration is $43 \%$ versus $28 \%$ in the optimized solution with mixed criterion 1 . This result is not surprising because by decreasing the thickness of the tank insulation, we can expect to increase the collector efficiency.

\section{- Exergy issue}

The solution obtained with the exergy optimization shows very high efficiency ( $\eta$ ex=97\%). The exergy criterion made the collector work with a high flow rate and a large tank volume so as to reduce the collector temperature. The quality of the input exergy is therefore very low. In addition, the exergy criterion tends to minimize the use of the auxiliary heater, which means a large collector area and high solar energy Qsol supplied to the tank. The maximum values authorized by the three optimized parameters (flow rate, area and volume) were determined by the optimization. On the other hand, the tank's thermal losses and the initial investment are penalized and the pay-back time is the highest. Furthermore, the large tank volume leads to high $Q l$ losses but limits the over-heating in spite of the large collector area.

If we consider the mixed criteria, the most advantageous solutions do not have the highest exergy efficiency $(\eta \mathrm{ex}=33 \%$ in mixed criterion 1$)$, making it difficult to classify the solutions solely on the exergetic criterion. It would be necessary to mix the exergetic and financial criteria.

We have also considered a modified exergy parameter taking into account not the exergy of the heat entering the solar panel as in equation (23), but rather the exergy of the incident solar radiation, following the Petela expression (Petela, 2003). This criterion presented low values between 17\% (using equation (23) for optimization) and 25\% (using the Petela expression for optimization), because solar radiation has a high exergy content. The optimization also leads to a large solar collector $\left(9.75 \mathrm{~m}^{2}\right)$, a large storage tank (587 $\left.\mathrm{l}\right)$ and operation at a high flow rate $\left(65 \mathrm{l} / \mathrm{hm}^{2}\right)$. 


\section{- Environmental impact}

To reduce greenhouse gas emissions, optimized solutions with mixed criterion 1 can save $309 \mathrm{~kg}$ of CO2 per year compared to the conventional solution, corresponding to $94 \mathrm{~kg}$ more (309-215) compared to the standard solar heating installation. Concerning the fossil and fissile resources, the annual primary energy savings is 10,548 kWh-ep with solar energy according to mixed criterion 1, and $7386 \mathrm{kWh}$-ep in the standard solar installation.

\section{- Cost}

The pay-back time of the basic solar installation is 15.2 years, and 12.9 years for the solution obtained with the optimization using mixed criterion 1. The annual savings (auxiliary heater, pump and controller) thus obtained is $288 €$ (taxes included); the annual cost of electricity consumption in the conventional installation being estimated at $553 €$. The payoff period is relatively high given the current cost of electricity in France. This is not the case in all European countries such as Denmark, where the price of electricity is twice as high. Even if energy prices continue to increase, thus reducing the payoff period, it is crucial to attempt to reduce the investment cost of a SDHWS installation using, for example, polymer materials.

\section{- Comfort}

All the solar solutions (standard or optimized) present a more advantageous distribution of hot water temperature Thw in terms of comfort than the conventional solution (see the temperature distribution when Thw is below $50^{\circ} \mathrm{C}$ in Fig. 5). The $Q d_{\text {pen }}$ penalty integrated into the various optimization criteria makes it possible to optimize the solutions with a high comfort level ( $T h w$ is close to the set-point $55^{\circ} \mathrm{C}$ ).

The conventional solution is penalized by thinner tank insulation. Moreover, the solar energy supplied to the tank increases its temperature during the day, tapping being defined in an unpredictable way according to the method described in (Shah, 2002). It can be seen that solar energy provides both energy savings and improved comfort.

\subsubsection{Relations between the energetic criteria}

We estimated three important energetic criteria (Fsol, Fsav- $f$ and COP). Improving these three criteria requires an increase in collector area (which reduces the productivity of the collector and increases the investment cost). The criterion, that seems a priori the most valuable is fractional savings $F s a v-f$ compared to an equivalent conventional installation. The relation between this criterion and the two others needs to be calculated for better comparison. 
It is easy to determine the relation between Fsav-f and $C O P$ from the equations. Assuming a water tap temperature of $55^{\circ} \mathrm{C}\left(Q f_{\text {pen }}\right.$ equals zero):

Fsav- $f=1-(Q d / C O P+Q p a r) / Q f_{\text {conv }}$

The function $F s a v-f=\mathrm{f}(C O P)$ increases as long as $Q d$ and $Q p a r$ remain fairly constant and $Q f_{\text {conv }}$ is fixed. It is thus possible to replace the Fsav-f optimization criterion with the $C O P$ criterion. The relation between $F s a v-f$ and $C O P$ is easily defined in the following conditions:

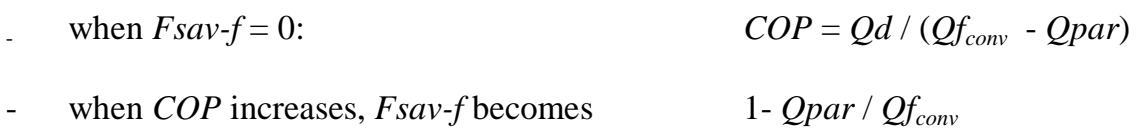

Fig. 6 shows how this function evolves.

The solar fraction Fsol gives important information on the installation sizing: how much of the energy supplied by the system is solar? Nevertheless, the solar fraction Fsol is not representative of the installation's global energy performance because the solar energy supplied to the tank can be useless (high solar production during summer) or lost (high tank losses because of large volume or insufficient insulation). The solar fraction Fsol determined in summer contributes additional information on the sizing of the installation for high solar radiation.

Qualitative considerations allow one to study the function $F s a v-f=\mathrm{f}(F s o l)$ :

- When Fsol tends towards 0, the solar energy supplied to the tank becomes very low. We thus approach the conventional installation and we can consider that Fsav-f tends towards 0 . It is actually a bit more complicated because the standard solar and conventional installations are very different (for example, there is more tank insulation in the first case).

- It is relatively easy to obtain $F$ sol $=100 \%$ by over-sizing the collector area and the tank volume (we could even reduce its insulation) so as to supply a large amount of solar energy and thus obtain $Q s o l=Q d$. On the other hand, obtaining Fsav- $f=100 \%$ is unrealistic because of inadequate solar energy incident at certain times during the winter.

- The various solutions studied are presented in Fig. 7. The maximum for Fsav-f is slightly lower than $70 \%$, which corresponds approximately to $\mathrm{Fsol}=90 \%$.

Since the function is not monotonic, we cannot use Fsol as a criterion for optimization.

\subsubsection{Comparison of the various optimization methods}


We also used the Hooke-Jeeves method and the Nelder-Mead-O'Neill and Coordinate Search methods to compare $L C C$ optimization (the same initial values are used). We used the Hooke-Jeeves method with initial penalizing values $\left(2 \mathrm{~m}^{2}, 0.2 \mathrm{~m}^{3}\right.$ and $\left.65 \mathrm{l} / \mathrm{hm}^{2}\right)$ for the $L C C$ as well. The $L C C$ values obtained at the end of the optimization are very close for all the methods.

\subsection{Global evaluation approach}

The most advantageous optimization criteria have been shown through the financial and energy savings. Here we study a global evaluation of an installation based on a radar diagram of savings with regard to a reference installation compared to the conventional installation. The radar diagram indicates three fractional savings that we believe to be essential in savings relative to the $L C C$ (Fsav-LCC), primary energy $(F s a v-p)$ and greenhouse gas emissions ( $\left.\mathrm{Fsav}-\mathrm{CO}_{2}\right)$. The first evaluation criterion is important for the installation owner and the last two are important from an environmental point of view (limitation of greenhouse gas emissions and conservation of fossil or fissile resources). For readability, the best performance corresponds to the outside triangle (and conversely).

Fig. 8 shows that the standard solution is the least beneficial. The lines relative to the various solutions are parallel between $F s a v-p$ and $\mathrm{Fsav}_{-} \mathrm{CO}_{2}$ because these two criteria are equivalent in terms of the electricity choice for the auxiliary heater (it would obviously be interesting to compare installations with various auxiliary energies).

\section{Conclusion}

We have compared various optimization criteria for a SDHWS with an electric auxiliary heater. It is important to consider criteria integrating both energy and financial aspects. The $L C C$ optimization criteria, mixed 1 and mixed 4, are the most indicative. The solutions obtained after optimization show that it is better to oversize the collector area than the tank volume (the thermal losses and financial cost are high).

Even if the results obtained are closely related to conditions in France through the parameters selected, a number of general conclusions can be drawn. For example, the evaluation criteria used for the solar installations are often not representative of actual performance because they are often based on the solar energy supplied to the tank (solar fraction and productivity) without considering the auxiliary heater. In addition, the current environmental problems require that the greenhouse gas emissions and the consummate 
primary energy also be considered. This is the reason why we developed a new representation of global evaluation in the form of radar diagram based on fractional savings $F s a v-p, F s a v-\mathrm{CO}_{2}$ and $F s a v-L C C$.

The highest-performance solutions obtained should not be considered ideal because they are not necessarily realistic given, on the one hand, the sizing restrictions related to the materials available, and, on the other hand, the simplifying hypotheses advanced. For example, only three optimization parameters were considered and we did not take into account the technological precautions necessary when the collector is oversized. Nonetheless, this article proposes a starting point for studies that are more complete (taking other countries into account, etc.) and more realistic.

Substantial work remains to be done to obtain a reliable tool for evaluation and optimization of the numerous SDHW configurations. It would be particularly necessary to:

- $\quad$ integrate the various design possibilities: direct coupled photovoltaic and pump, the energy choice for the auxiliary heater.

- modify the hypotheses so that countries other than France could be studied. Nevertheless, the price of a $\mathrm{kWh}$ of electricity is relatively low in most European countries (on average approximately $14 \mathrm{c} € / \mathrm{kWh}$ ). The payoff period therefore risks being relatively long in general. Even if a rise in price can be expected in the coming years, it is important to design new, less expensive SDHWS using, for example, polymer materials and simplifying the systems.

- $\quad$ evaluate more precisely the financial cost: manpower depending on the component sizing (collector area, etc.), the price of the devices to prevent over-heating during summer, the cost of the insulation (tank and pipes), etc. It would also be necessary to integrate various changes in the price of energy.

- $\quad$ add parameters to be optimized: height of the auxiliary heater in the tank, the thickness of insulating material, etc.

- integrate other optimization parameters related to the production of primary energy. For example, the availability of water in certain arid areas poses the problem of producing electricity based on a cycle vapor power plant.

\section{Nomenclature}

\begin{tabular}{|cl}
\hline Symbols & \\
$A c$ & collector area $\quad\left(\mathrm{m}^{2}\right)$ \\
$A I$ & additional investment between non-solar and solar DHWS $(€)$ \\
$C O P$ & coefficient of performance \\
$d$ & discount rate
\end{tabular}




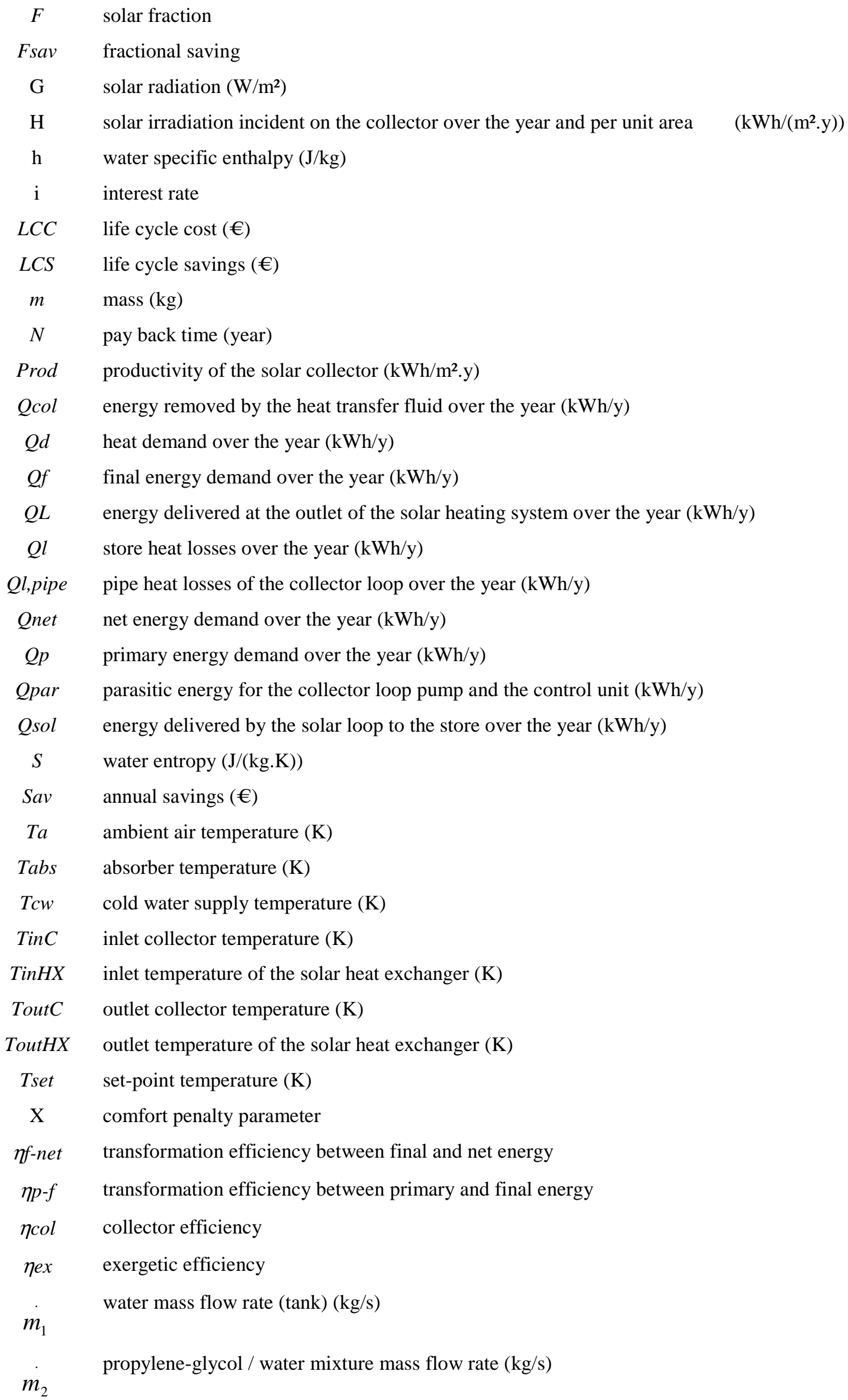


$\dot{m}_{3}$

water tap mass flow rate $(\mathrm{kg} / \mathrm{s})$

Subscripts

aux auxiliary heater

$f \quad$ final energy

$p \quad$ primary energy

pen penalty energy due to water tap temperature (comfort)

\section{ANNEX 1: the financial costs}

a) conventional installation (taxes included)

- $\quad$ Tank (200 1, vertical): $550 €$

- $\quad$ Manpower: $300 €$

- Annual maintenance $=20 € /$ year

Annual operation costs:

- $\quad$ Final energy consumption (electricity): $0.1074 € / \mathrm{kWh}$

\section{b) standard solar installation}

\section{$\underline{\text { Grants and VAT: }}$}

- $\quad$ grants: $800 €$

- Tax reduction: $50 \%$ on the equipment (grant have to be deduct)

- $\quad$ VAT: $5.5 \%$

Equipment costs (tax free):

- collector: $360 € / \mathrm{m}^{2}$

- $\quad$ tank: $3500-4500 € / \mathrm{m}^{3}$

- $\quad$ pipe: $10 € H T / m$

Other equipment cost: $575 €$ (tax free)

- $\quad$ Manpower: $1600 € /$ installation

- Maintenance: $100 € /$ year

Determination of the solar investment (taxes included)

- $\quad$ Tax reduction $=50 \% *($ equipment - grants $*$ equipment $/($ equipment + manpower $))$

- $\quad$ equipment $€=c 1+c 2 * \mathrm{Sc}+c 3 * V+c 4 *$ Lpipe 


$$
\begin{aligned}
& c 1=600 € \\
& c 2=380 € / \mathrm{m}^{2} \text { (collector) } \\
& c 3=4220 € / \mathrm{m}^{3} \text { (tank) } \\
& c 4=10 € / \mathrm{m} \text { (pipe) } \\
& -\quad \text { manpower }=1688 €
\end{aligned}
$$

Annual maintenance cost: $105 € /$ year (taxes included)

\section{ANNEX 2: description of the installations}

\section{a) conventional installation}

- Volume: 2001

- $\quad$ Tank insulation: $3.3 \mathrm{~cm}$

- Auxiliary heater: $3000 \mathrm{~W}$

- Diameter: $0.434 m$

- $\quad$ Tank height: $1.35 \mathrm{~m}$

- $\quad$ Tank losses: $\mathrm{UA}=4 \mathrm{~W} / \mathrm{K}$

b) standard solar installation

Clipsol TGD solar collector $(\mathrm{X}=6, \mathrm{Y}=2)$

- $\quad$ area: $5.963 \mathrm{~m}^{2}$

- collector efficiency: $\eta=0.73$

- collector loss coefficients $\mathrm{a}_{1}=4.26 \mathrm{~W} / \mathrm{m}^{2} . \mathrm{K}$ and $\mathrm{a}_{2}=0.0047 \mathrm{~W} / \mathrm{m}^{2} . \mathrm{K}^{2}$

Pipes:

- $\quad$ Diameter 16/18 mm

- Insulation thickness: $2.2 \mathrm{~cm}$ (conductivity: $0.04 \mathrm{~W} / \mathrm{mK}$ )

- $\quad$ Total length: $28 \mathrm{~m}$

- Fraction of glycol (propylene-glycol / water mixture): $20 \%$

Tank:

- Volume: 4001

- insulation: $6 \mathrm{~cm}$ (conductivity: $0.037 \mathrm{~W} / \mathrm{mK}$ )

- Auxiliary heater: $3000 \mathrm{~W}$

- Tank height: $1.811 \mathrm{~m}$ 
- $\quad$ Tank losses: $3.5 \mathrm{~W} / \mathrm{K}$

- Heat exchanger tube inside diameter / area: $1.5 \mathrm{~cm} / 1.69 \mathrm{~m}^{2}$

- $\quad$ Auxiliary heater relative height: 0.5

- Heat exchanger input / output relative heights: 0.27 / 0.07

pump: $10 \mathrm{~W}\left(10 \mathrm{l} / \mathrm{hm}^{2}\right), 35 \mathrm{~W}\left(50 \mathrm{l} / \mathrm{hm}^{2}\right), 60 \mathrm{~W}\left(90 \mathrm{l} / \mathrm{hm}^{2}\right)$

Controller: $5 \mathrm{~W}$

\section{REFERENCES}

ADEME, 2005. Note de cadrage sur le contenu $\mathrm{CO}_{2} \mathrm{du} \mathrm{kWh}$ par usage en France, 5p. www2.ademe.fr.

Badescu, V., Staicovici, M.D., 2006. Renewable energy for passive house heating: Model of the active solar heating system. Energy and Buildings, Volume 38, Issue 2, 129-141.

Bakos, G.C., Tsagas, N. F., 2003. Technoeconomic assessment of a hybrid solar/wind installation for electrical energy saving. Energy and Buildings, Volume 35, Issue 2, 139-145

Bales, C., 2002. Generic system 11: Space heating store with DHW load side heat exchangers and auxiliary boiler. Report of IEA SHC, task 26, solar combisystems, p. 63.

Cardinale, N., Piccininni, F., Stefanizzi, P., 2003. Economic optimization of low-flow solar domestic hot water plants. Renewable Energy, Volume 28, Issue 12, 1899-1914

Chow, T.T., Fong, K.F., Chan, A.L.S., Lin, Z., 2006. Potential application of a centralized solar water-heating system for a high-rise residential building in Hong Kong. Applied Energy, Volume 83, Issue 1, $42-54$

Duffie, J.A., Beckman, W.A., 1991. Solar Engineering of thermal processes, 2nd ed New York : John Wiley \& Sons, p. 919. 
Fernandez-Seara, J., Uhia, F.J., Sieres, J., 2007. Experimental analysis of a domestic electric hot water storage tank. Part I: Static mode of operation, Applied Thermal Engineering 27, 129-136

Fuller, S.K., Petersen, S.R., 2002. Energy Price Indices and Discount Factors for Life-Cycle Cost Analysis (Annual Supplement to NST Handbook 135 and NBS Special Publication 709) http://fire.nist.gov/bfrlpubs/build02/PDF/b02017.pdf

Gabriele G.A., Ragsdell K.M., 1984. Optilib. An optimization program library: user manual. Colombia: College of Engineering University of Missouri.

Gunerhan, H., Hepbasli, A., 2007. Exergetic modeling and performance evaluation of solar water heating systems for building applications, Energy and Buildings, volume 39, issue 5, 509-516.

A. Hepbasli, 2007. Exergetic modeling and assessment of solar assisted domestic hot water tank integrated ground-source heat pump systems for residences, Energy and Buildings, volume 39, issue 12, 1211-1217.

ISO,1999. Norme ISO/FDIS 9488. Solar energy, vocabulary. Projet final de norme internationale, p. 48.

Jordan, U., Furbo, S., 2005. Thermal stratification in small solar domestic storage tanks caused by draw-offs. Solar Energy, Volume 78, Issue 2, 291-300

Kalogirou, S.A., 2004. Optimization of solar systems using artificial neural-networks and genetic algorithms. Applied Energy, Volume 77, Issue 4, 383-405

Klein S.A. et al., 1996. TRNSYS a transient system simulation program, version 14.2. Solar Energy Laboratory, University of Wisconsin-Madison, reference manual, WI 53706

Krause, M., Vajen, K., Wiese F., Ackermann, H., 2002. Investigations on optimizing large solar thermal systems. Solar Energy, Volume 73, Issue 4, 217-225 
Le Pierrès, N., 2005. Procédé solaire de production de froid basse température $\left(-28^{\circ} \mathrm{C}\right)$ par sorption solidegaz, thèse de l'université de Perpignan.

Lima, J.B.A., Prado R.T.A., Taborianski, V.M., 2006. Optimization of tank and flat-plate collector of solar water heating system for single-family households to assure economic efficiency through the TRNSYS program. Renewable Energy, Volume 31, Issue 10, 1581-1595

Lund, P.D., 2005. Sizing and applicability considerations of solar combisystems. Solar Energy, Volume 78, Issue $1,59-71$

Petela, R., 2003, Exergy of undiluted thermal radiation. Solar Energy, Volume 74, Issue 6, 469-488

Peuser, F.A., Remmers, K.H., Schnauss, M., 2005. Installations solaires thermiques. Editions Le Moniteur, p. 403.

Prud'homme, T., Gillet, D., 2001. Advanced control strategy of a solar domestic hot water system with a segmented auxiliary heater. Energy and Buildings, Volume 33, Issue 5, 463-475

SAE, 1995. Society of Automotive Engineers (SAE), "Life Cycle Cost", Reliability, Maintainability, and Supportability. Guidebook, 3rd edition, Warrendale, PA.

Salazar, J.P.L, Abreu, S.L., Colle, S., Reguse, W., 2003. Optimization of a compact solar domestic hot water system for low-income families with peak demand and total cost constraints. ISES, Göteborg, Sweden, p.6.

Shah, L. J., 2002. A solar combisystem based on a heat storage with three internal heat exchangers, IEA task 26, BYG-DTU SR-02-19, p. 99

Singh, N., Kaushikb, S.C, Misra, R.D., 2000. Exergetic analysis of a solar thermal power system, Renewable Energy 19, 135-143 
Sorin, M., Spinner, B., Stitou, D., 2002. Thermodynamic techniques for the conceptual design of thermochemical refrigerators using two salt materials, Chemical Engineering Science, Volume 57, Issue 19, 4243-4251

Stitou, D., Spinner, B., Satzger, P., Ziegler, F., 2000. Development and comparison of advanced cascading cycles coupling a solid/gas thermochemical process and a liquid/gas absorption process, Applied Thermal Engineering, Volume 20, Issue 14, 1237-1269

Torres-Reyes, E., Cervantes de Gortari, J., 2001. Optimal performance of an irreversible solar-assisted heat pump, Exergy Int. J. 1(2), 107-111

Torres-Reyes, E., Navarrete-Gonzalez, J.J., Zaleta-Aguilar, A., Cervantes-de Gortari, J., 2003. Optimal process of solar to thermal energy conversion and design of irreversible flat-plate solar collectors, Energy 28 , 99-113

Trillat-Berdal, V., Souyri, B., Fraisse, G., 2006. Experimental study of a ground-coupled heat pump combined with thermal solar collectors. Energy and Buildings, Volume 38, Issue 12, 1477-1484

Weiss, W., 2003. Solar heating systems for houses, a design handbook for solar combisystems. James and James. IEA, p. 313.

Wetter, M., Wright, J., 2003. Comparison of a generalized pattern search and genetic algorithm optimization method. Eighth International IBPSA Conference. Eindhoven, Netherlands, August 11-14, 1401-1408

Wetter, M., 2004. GenOpt, Generic Optimization Program. User Manual, Lawrence Berkeley National Laboratory, Technical Report LBNL-54199, p. 109

Xiaowu, W., Ben, H., 2005. Exergy analysis of domestic-scale solar water heaters, Renewable and Sustainable Energy Reviews, Volume 9, Issue 6, 638-645 
Zmeureanu, R., Wu, X. Y., 2007. Energy and exergy performance of residential heating systems with separate mechanical ventilation, Energy 32, 187-195 
Table 1. Improvement obtained for each optimized criterion

\begin{tabular}{|c|c|c|c|c|}
\hline Criterion & Performance function & Standard & Optimized & Improvement \\
\hline Energy & Fsav- $f$ & $47.0 \%$ & $68.1 \%$ & $45 \%$ \\
Exergy & $\eta e x$ & $39.9 \%$ & $97.4 \%$ & $144 \%$ \\
Cost & LCC & $9653 €$ & $8729 €$ & $10 \%$ \\
Mixed 1 & Fsav-f* Fsav-LCC & $2.7 \%$ & $9.7 \%$ & $256 \%$ \\
Mixed 2 & Qmin / Qsol & 1.8 & 0.8 & $54 \%$ \\
Mixed 3 & AI / Qf-sav & $0.94 € / \mathrm{kWh}$ & $0.82 € / \mathrm{kWh}$ & $13 \%$ \\
\hline
\end{tabular}

Table 2. Evaluation criteria for the installations (standard solar, optimized solar and conventional systems)

\begin{tabular}{|c|c|c|c|c|c|c|c|c|c|}
\hline & & \multirow{2}{*}{$\begin{array}{c}\text { standard } \\
\text { (solar) }\end{array}$} & \multicolumn{6}{|c|}{ OPTIMZATION CRITERIA } & \\
\hline & & & energy & exergy & $\mathrm{LCC}$ & $\operatorname{mixed} 1$ & $\operatorname{mixed} 2$ & mixed 3 & \\
\hline & & 4 & 10 & 10 & 8.3 & 9.9 & 10 & 5 & \\
\hline & \multirow{2}{*}{$\begin{array}{l}\text { EVALUATION } \\
\text { CRITERIA }\end{array}$} & 0.400 & 0.400 & 0.600 & 0.313 & 0.313 & 0.313 & 0.300 & Vtank (m3) \\
\hline & & 50 & 20.0 & 65.0 & 17.2 & 17.2 & 19.1 & 23.8 & $Q\left(1 / h^{2}\right)$ \\
\hline \multirow{18}{*}{ ENERGY } & $\mathrm{H}$ & 1177 & 1177 & 1177 & 1177 & 1177 & 1177 & 1177 & \\
\hline & prod & 512 & 342 & 357 & 368 & 330 & 327 & 472 & \\
\hline & $7 \mathrm{col}$ & 43 & 29 & 30 & 31 & 28 & 28 & 40 & \\
\hline & Fsol & 54 & 90 & 95 & 80 & 86 & 86 & 62 & \\
\hline & $F_{\text {sol }}$ (summer) & 110 & 163 & 183 & 145 & 151 & 151 & 122 & \multirow{2}{*}{$\begin{array}{r}\text { installation } \\
\text { (non solar) }\end{array}$} \\
\hline & $F_{\text {sol }}$ & 44 & 69 & 67 & 66 & 69 & 70 & 53 & \\
\hline & $C O P$ & 1.39 & 2.35 & 2.04 & 2.28 & 2.51 & 2.53 & 1.75 & 0.73 \\
\hline & $Q L$ & 3385 & 3418 & 3438 & 3371 & 3378 & 3379 & 3333 & 3162 \\
\hline & Qsol & 1816 & 3076 & 3273 & 2693 & 2893 & 2910 & 2071 & \\
\hline & $\mathrm{Ql}$ & 749 & 1051 & 1450 & 788 & 844 & 850 & 630 & 952 \\
\hline & Qi,pipe & 342 & 532 & 495 & 511 & 542 & 543 & 414 & \\
\hline & Qnet-aux & 2319 & 1384 & 1601 & 1406 & 1279 & 1270 & 1810 & 4138 \\
\hline & Qd-pen & 160 & 102 & 35 & 259 & 241 & 237 & 365 & 749 \\
\hline & Qpar & 115 & 78 & 117 & 76 & 75 & 76 & 87 & \\
\hline & Qf-sav & 2420 & 3503 & 3305 & 3316 & 3470 & 3481 & 2768 & \\
\hline & $Q p-s a v$ & 7386 & 10650 & 10066 & 10083 & 10548 & 10584 & 8426 & \\
\hline & Fsav-f & 47.0 & 68.1 & 64.2 & 64.5 & 67.4 & 67.7 & 53.8 & \\
\hline & $F_{s a v-p}$ & 47.4 & 68.3 & 64.6 & 64.7 & 67.7 & 67.9 & 54.0 & \\
\hline EXERY & rex & 40 & 40 & 97 & 30 & 33 & 36 & 26 & \\
\hline \multirow[t]{2}{*}{$\mathrm{CO} 2$} & $m_{\infty O 2}$ & 215 & 312 & 294 & 295 & 309 & 310 & 246 & \\
\hline & $F_{\text {Sav-CO2 }}$ & 47.0 & 68.1 & 64.2 & 64.5 & 67.4 & 67.7 & 53.8 & \\
\hline \multirow[t]{12}{*}{$\overline{\mathrm{COST}}$} & manpower & 1688 & 1688 & 1688 & 1688 & 1688 & 1688 & 1688 & 300 \\
\hline & equipment & 3920 & 6200 & 7000 & 5185 & 5803 & 5850 & 3900 & 550 \\
\hline & tax credit & 1680 & 2786 & 3178 & 2291 & 2591 & 2615 & 1671 & \\
\hline & grant & 800 & 800 & 800 & 800 & 800 & 800 & 800 & \\
\hline & $\mathrm{Al}$ & 2278 & 3452 & 3860 & 2932 & 3249 & 3273 & 2267 & \\
\hline & annual maintenance & 105 & 105 & 105 & 105 & 105 & 105 & 105 & 20 \\
\hline & annual operation & 293 & 176 & 198 & 196 & 180 & 179 & 255 & 553 \\
\hline & annual Sav & 175 & 291 & 270 & 271 & 288 & 289 & 212 & \\
\hline & $\angle C C$ & 9653 & 8920 & 9677 & 8729 & 8775 & 8778 & 9031 & 10247 \\
\hline & $\operatorname{LCS}$ & 594 & 1327 & 570 & 1518 & 1472 & 1469 & 1216 & \\
\hline & $N$ & 15.2 & 13.6 & 16.9 & 12.3 & 12.9 & 12.9 & 12.1 & \\
\hline & Fsav-LCC & 5.8 & 13.0 & 5.6 & 14.8 & 14.4 & 14.3 & 11.9 & \\
\hline MIXED 1 & $F_{\text {SaV }-f}{ }^{*} F_{\text {SaV }-L C C}$ & 2.73 & 8.82 & 3.57 & 9.55 & 9.69 & 9.70 & 6.39 & \\
\hline MIXED 2 & Qmir/Qsol & 1.78 & 0.82 & 0.94 & 0.91 & 0.82 & 0.81 & 1.35 & \\
\hline MIXED 3 & $\mathrm{Al} / \mathrm{Qf}$-saV & 0.94 & 0.99 & 1.17 & 0.88 & 0.94 & 0.94 & 0.82 & \\
\hline
\end{tabular}




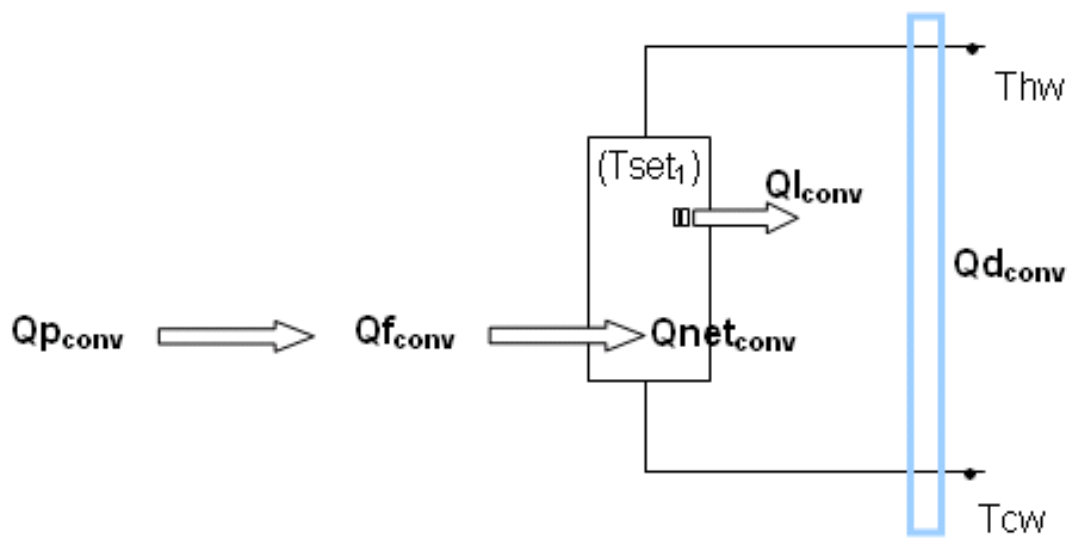

Fig. 1. Conventional domestic hot water system

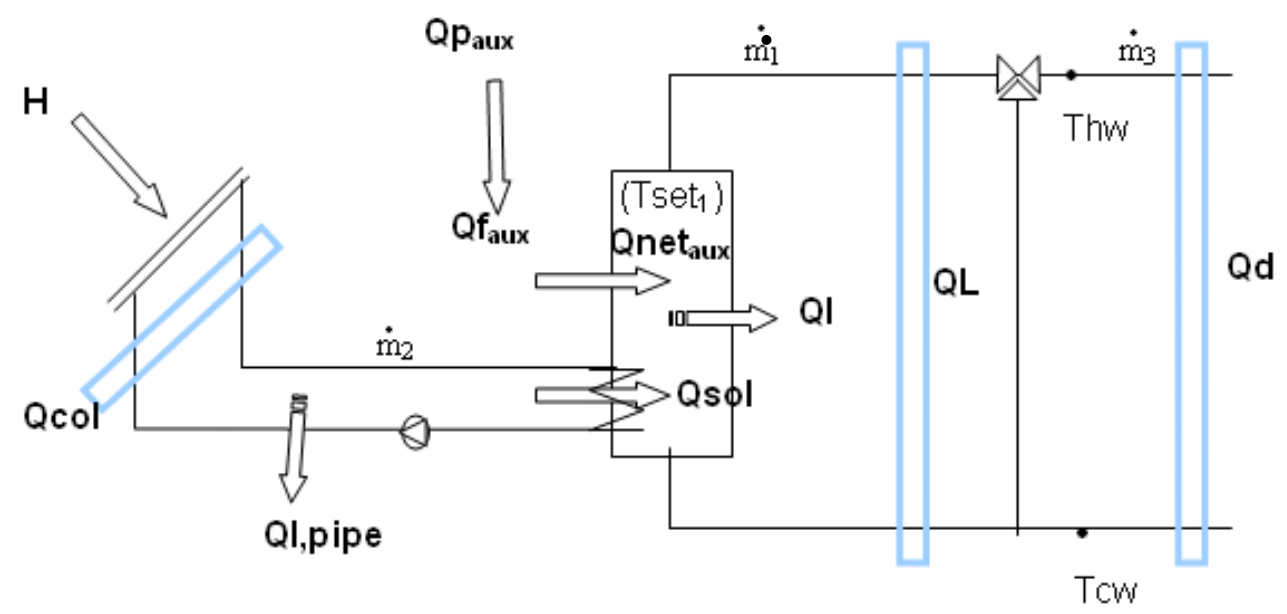

Fig. 2. Solar installation with integrated auxiliary heater

optimization : Hooke-Jeeves

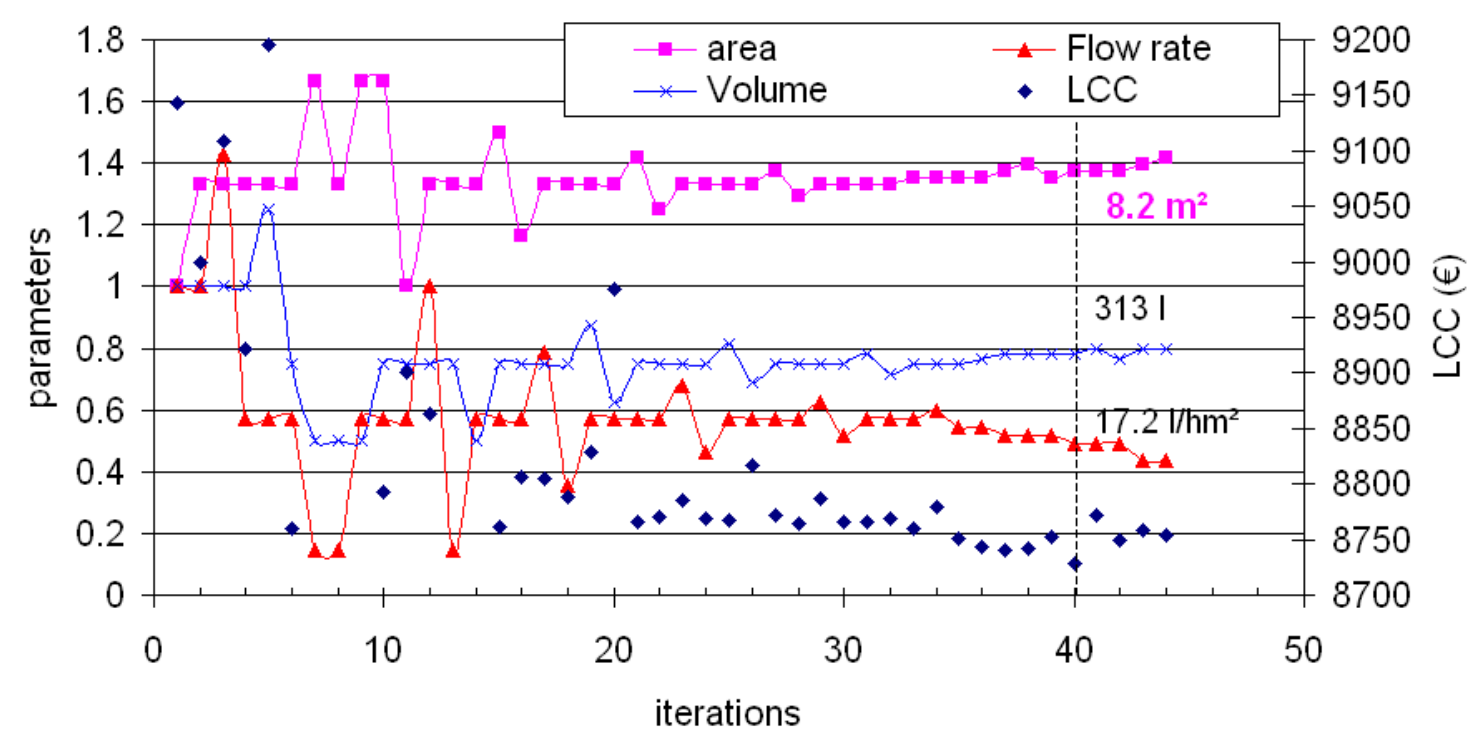

Fig. 3. Example of LCC optimization results 


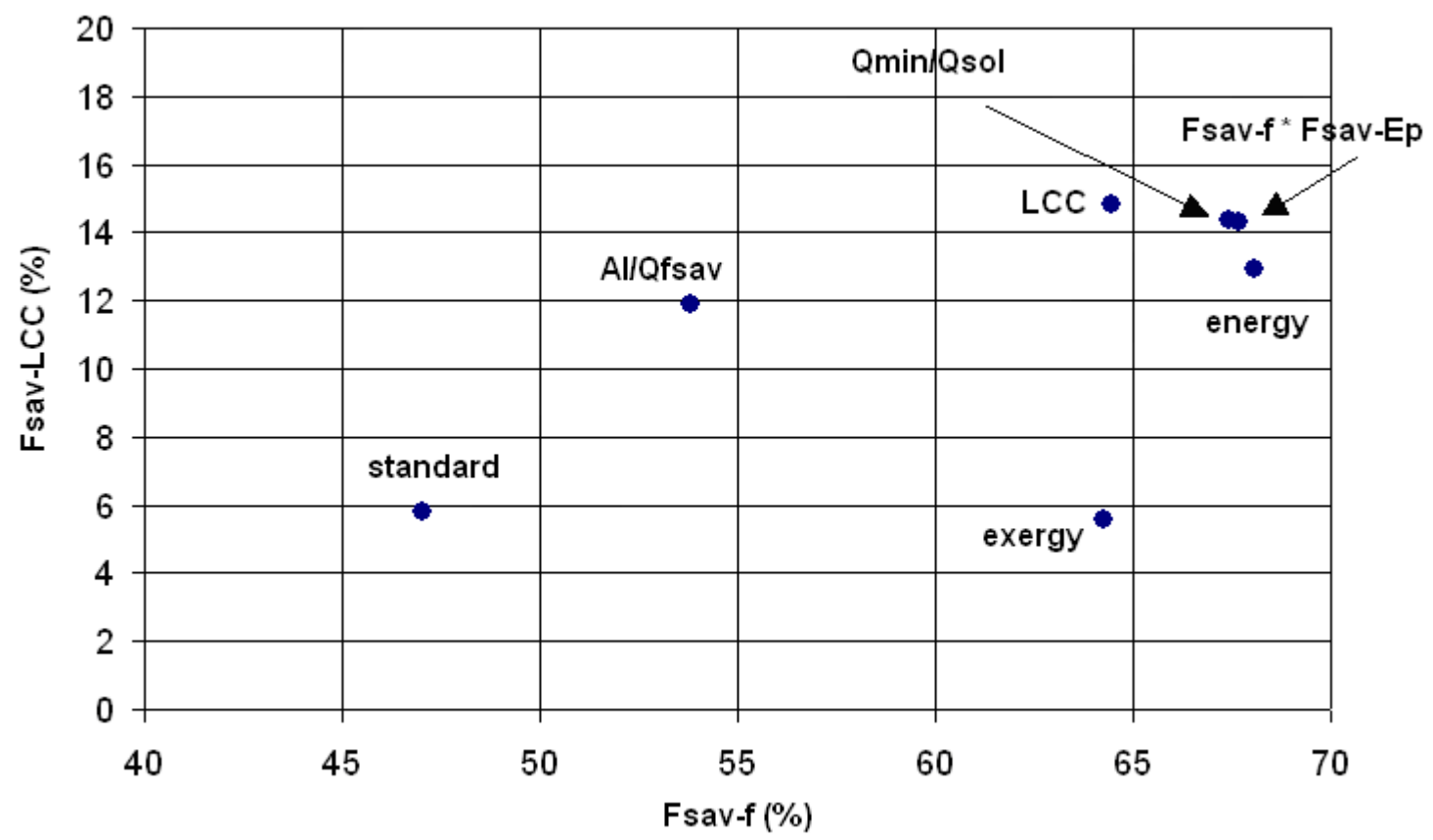

Fig. 4. Energy and financial evaluation



Fig. 5. Hot water temperature distribution (when water is tapped) 


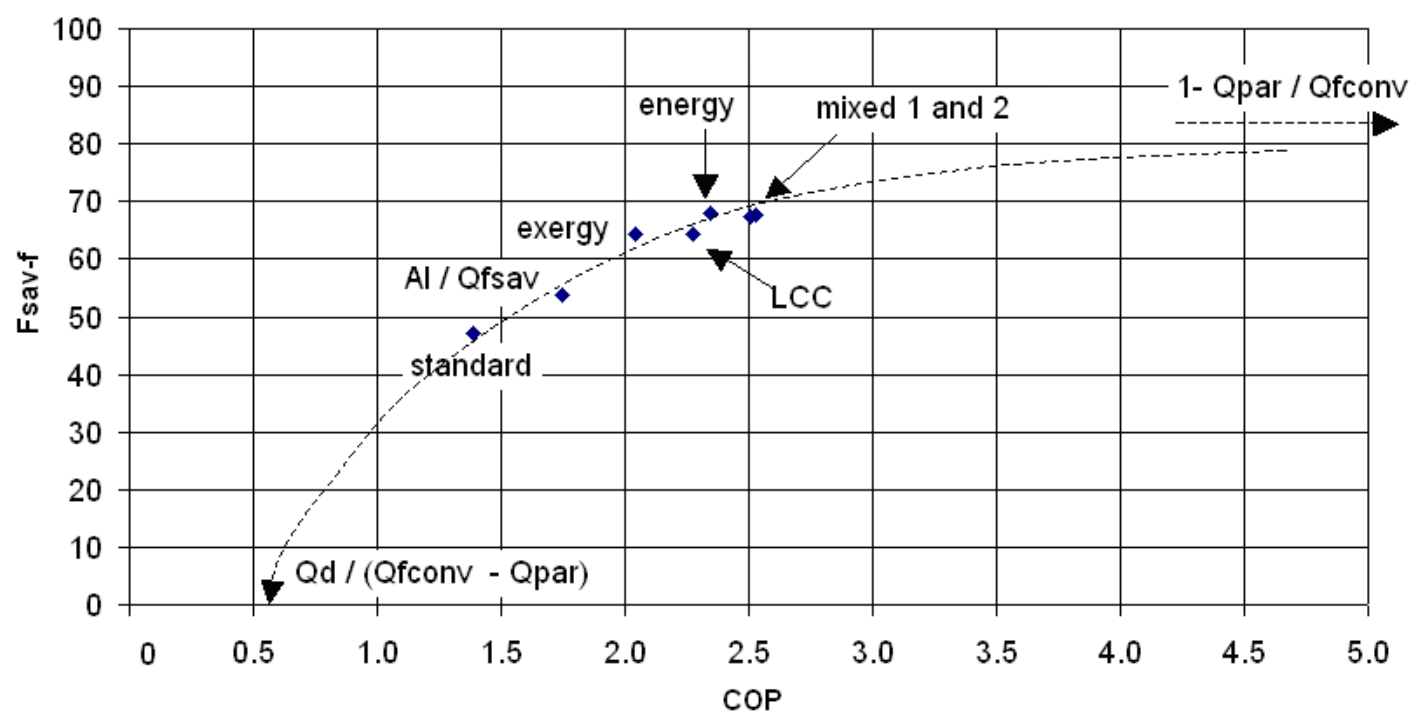

Fig. 6. Relation between $F s a v-f$ and $C O P$

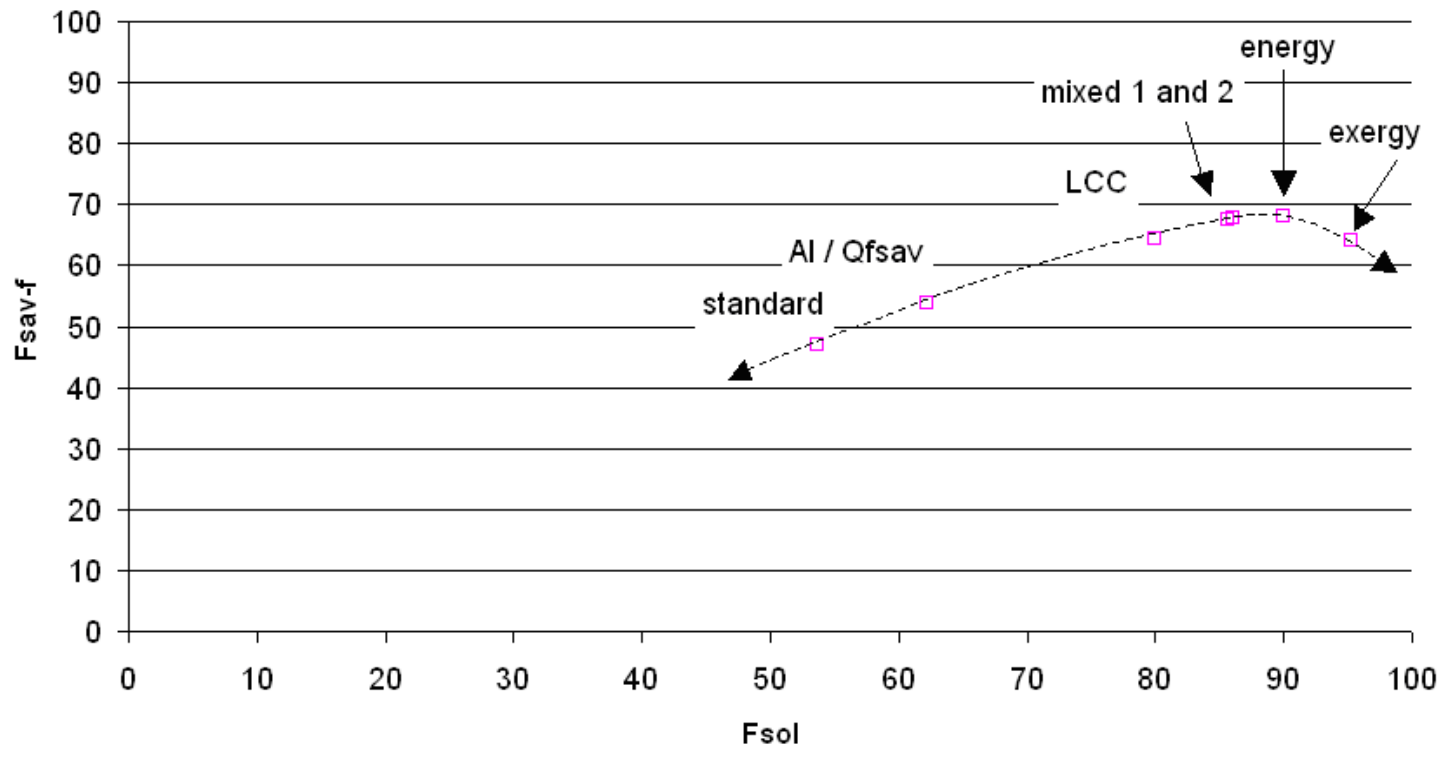

Fig. 7. Relation between Fsav- $f$ and $F$ sol 


\section{Fsav-CO2}

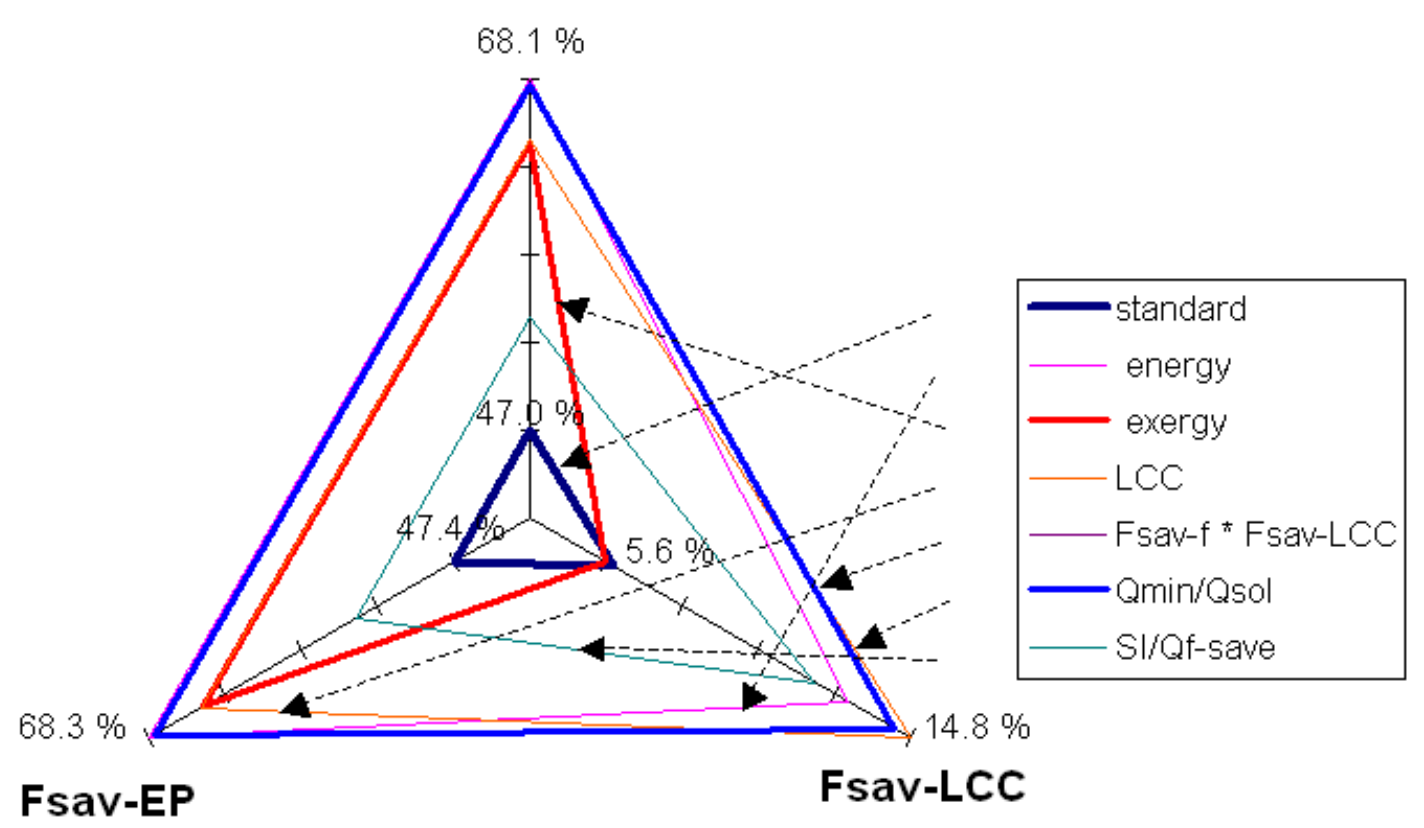

Fig. 8. Performance for a global evaluation 